\title{
O MINISTÉRIO PÚBLICO BRASILEIRO E A JUSTIÇA CONSENSUAL
}

\author{
Antonio Carlos DA PONTE \\ Procurador de Justiça Criminal no Estado de São Paulo \\ Catedrático de Derecho Penal \\ en la Pontificia Universidad Católica de São Paulo \\ Director del CEAF/ESMP \\ acdaponte@uol.com.br \\ Pedro Henrique Demercian \\ Procurador de Justiça Criminal \\ no Estado de São Paulo \\ Professor Doutor, pela PUC/SP \\ esmp-diretoria@mpsp.mp.br
}

\begin{abstract}
RESUMEN
Há uma tendência mundial para o chamado processo penal de resultados, que tem por escopo, em apertada sintese: a) solução rápida e eficiente dos litígios; b) a desburocratização da Justiça e sua maior aproximação ao ser consumidor; c) permitir que o Magistrado e Ministério Público, mais do que solucionadores de mazelas e doenças, atentem para uma postura preventiva e, quando não possível, de mediadores de conflitos. É nesse contexto que se insere a Justiça Consensual, em cuja espécie é possivel identificar os modelos de justiça negociada (transação penal, suspensão condicional do processo, colaboração premiada, etc.). Evidencia-se, portanto, uma clara antinomia e contraposição entre o consenso e a justiça imposta ou conflitual. A justiça consensuada pode e deve ser adaptada ao modelo adotado em nosso país, na busca da eficiência, sem que, para tanto, sejam sacrificados os axiomas processuais clássicos.
\end{abstract}

Palabras clave: Ministério Público, eficiência, consenso, justiça racional.

\section{ABSTRACT}

There is a global trend for the so-called penal process of results, which succinctly covers: a) quick and effective case solving; b) justice Admin Simplicity and a better approach to consumers; c) allowance of both lawyer and Public Ministry prevention rather than actual healing, that not being the case, let them mediate. It is within this context that we include Consensual Justice, by which we may remark agreement justice models (penal transaction, conditional procedure suspension, bonused collaboration among others). We, therefore, notice a clear opposition and inconsistency between consensus and imposed or conflict justice. Consensus justice 
may and should be adapted to the pattern adopted in Spain, in a search for efficiency, yet without abstaining from classic procedural anthems.

Keywords: Public Office, consensual efficiency, rational justice.

\section{ZUSAMMENFASSUNG}

Es ist ein weltweiter Trend bin zu den sogenannten ergebnisorientierten Strafprozessen zu beobachten, und dieser umfasst, in groben Zügen: a) schnelle und effiziente Lösung der Rechtsstreite; b) die Entbürokratisierung der Justiz und stärkere Annäherung an den Verbraucher; c) die Ermöglichung, dass die Funktion des Richters und des Staatsanwalts über das Beheben von Verletzungen und Leiden hinausgeht hin zur Einnabme einer präventiven Haltung, und - sollte diese nicht möglich sein- ein Auftreten als Konfliktmediatoren.

In diesen juristischen Kontext fügt sich die einvernebmliche Justiz ein. In dieser Justizgattung kann man die verschiedenen Modelle der Verhandlungsjustiz (Strafabwicklung, bedingte Prozessaussetzung, Verständigung im Strafverfabren usw.) finden. Es zeigt sich hierbei folglich eine klare Antinomie und Gegenüberstellung zwischen der Konsensjustiz und der auferlegenden bzw. konfliktorientierten Justiz. Die einvernebmliche Justiz kann und sollte in unserem Land als Justizmodell zur Erlangung der Effizienz wabrgenommen werden, obne hierbei die klassischen Axiome des Prozessrechts aufzugeben.

Schlüsselwörter: Staatsanwaltschaft, konsenzeffizienz, rationale Justiz.

SUMARIO: I. INTRODUÇÃO.-II. BREVES NOTAS SOBRE A EVOLUÇÃO DO MINISTÉRIO PÚBLIÇO (DE 1946 A 1988).--III. A BUSCA PELA EFIĆIÊNCIA NA POLÍTICA CRIMINAL: A JUSTIÇA CONSENSUAL.-1. Aspectos introdutórios.-2. O processo penal de resultados: um modelo de Justiça consensual e racional.-IV. CONCLUSÕES.-V. BIBLIOGRAFÍA.

\section{INTRODUÇÃO}

Discorrendo, em meados do século passado, sobre a atuação moral do Ministério Público, André de Faria Pereira, em primorosa lição, deixou assentado que há muito o Parquet deixou de exercer o seu papel originário de advogado da coroa e instrumento de acusação sistemática ${ }^{1}$. Já àquela época afirmava-se que o órgão oficial da acusação era a própria personificação da justiça, não só por ser ente tutelar dos interesses jurídicos e sociais, mas, também, por atenuar os excessos da ação privada, muitas vezes inspirada no sentimento de vingança.

${ }^{1}$ Apud R. Lyra, Teoria e Prática da Promotoria Pública, 2. ${ }^{a}$ ed., Porto Alegre, Sérgio Antonio Fabris, 1989, p. 149. 
No exercício de tão nobres funções os Promotores de Justiça sempre estiveram vinculados ao julgamento soberano da própria consciência. Aqui se evidencia, por exemplo, sua independência e autonomia funcionais, que estão diretamente ligadas ao exercício privativo da ação penal ou o chamado monopólio da ação penal pública.

Em nosso País o avanço legislativo fez com que o Ministério Público atingisse uma liberdade de atuação que não tem precedentes no direito estrangeiro. No entanto, em tempos mais do que nunca maniqueístas, a interpretação da Constituição Federal e de todas as leis que dão suporte a uma atuação independente de Promotores de Justiça e Procuradores da República autoriza o questionamento: qual é a política de atuação desse órgão e o que se espera da Instituição?

Isto porque a existência deste órgão autônomo e independente da estrutura Estatal assegura sua atuação objetiva (com base do interesse público) mesmo face daqueles que detêm poder político, midiático e econômico. O Ministério Público, definitivamente, desagrada e sua atuação republicana «aborrece privilégios e abomina a formação de castas» (Sepúlveda Pertence, STF, Adin 1.828-2, medida liminar, DJU de 7/8/98, citado no «Informativo do STF», núm. 117, p. 3).

\section{BREVES NOTAS SOBRE A EVOLUÇÃO DO MINISTÉRIO PÚBLICO (DE 1946 A 1988)}

Em 1946 foi promulgada Constituição Federal, com inspiração eminentemente democrática, que dedicou ao Ministério Público maior magnitude. A despeito disso, o Procurador-geral da República era nomeado e demissível, ad nutum, pelo Presidente da República (cfr. art. 126) e não era escolhido dentre os Ministros do STF, o que representava a própria deturpação da figura do Chefe do Parquet, que se tornava, assim, um mero agente político do governo. Em outras palavras, o Procurador-geral da República detinha enormes poderes e responsabilidades, tendo de exercer seu mister com dignidade e justiça, mas sempre a mercê da vontade do governo. Daí o relevante desabafo de Themistocles Cavalcante, ao ser exonerado do referido cargo pelo Presidente da República: «...a situação do Procurador-geral da República é sempre uma situação de natureza instável, porque tem de colocar a sua consciência e os preceitos da Justiça, os encargos da Justiça, acima dos interesses e das paixões políticas» ${ }^{2}$.

\footnotetext{
${ }^{2}$ Cfr. M. Dias, Ministério Público Brasileiro, op. cit., t. I, p. 25.
} 
Essa feição do Ministério Público perdurou até 1964, com o rompimento da ordem constitucional e a instauração do regime militar. Nesse periodo vigorou no Brasil a Constituição outorgada de 1967, com as respectivas emendas, especialmente a de núm. 01/69, que vinculou a instituição ao Executivo e, posteriormente, a de núm. 08/77, que determinou, por lei complementar de iniciativa do Presidente da República, a organização da carreira no âmbito dos Estados.

Por essa época foi editada a Lei Complementar núm. 40/81, que estabeleceu as regras básicas para a estruturação e funcionamento dos Ministérios Públicos Estaduais. Apesar disso, a ideia de Ministério Público ainda estava vinculada à concepção de «Estado em Juízo», quer como advogado da União, quer como titular da ação penal, visto, de qualquer forma, como apêndice do governo em juízo, pensamento, por sinal, que, hodiernamente, tem seduzido políticos e até mesmo juristas de renome, ligados de uma maneira ou de outra à operação conhecida como lava-jato.

A política do Procurador-geral continuava vinculada ao pensamento do governo e, além disso, a própria titularidade da ação penal estava sujeita a grandes incertezas, até porque era definida na referida Lei Complementar e, portanto, não revestida da mesma rigidez e importância de uma regra constitucional. Apesar dessas grandes limitações, o Ministério Público não se envergava e foi protagonista na investigação e punição de crimes praticados durante os anos de chumbo, notadamente a punição do esquadrão da morte, tendo à frente intimoratos promotores de Justiça (Hélio Bicudo e Dirceu de Mello).

O reconhecimento social da atuação do Parquet ressurtiu na última reforma da Lei Fundamental da República. A Constituição Federal de 1988, alterou, substancialmente, o perfil do Ministério Público, afastando-o da conformação que hoje tem na grande maioria dos países da Europa Continental, onde, aliás, deita raízes a Instituição. Enfatizou-se a peculiar natureza jurídica desse órgão, que não integra e tampouco se submete à hierarquia do Estado-Aparato; o espaço de autonomia do Ministério Público passa a ser bastante distinto de outros entes Estatais, notadamente porque ele é, na verdade, o próprio fiscal do poder.

A partir de 1988, como se disse, o Ministério Público perdeu o papel de advogado do Estado e se transformou, definitivamente, em advogado da sociedade: a sociedade-governante.

A Carta Constitucional atribuiu-lhe o dever de zelar pelo respeito aos direitos assegurados na CF (art. 129, II), ressaltou-lhe o caráter de órgão de defesa dos interesses sociais (estabeleceu-se, nessa medida, a contraposição 
entre o estado-aparato e estado-comunidade). Esse aparente paradoxo na natureza da instituição reside no fato dela estar inserida no aparato estatal, mas com a função de defesa da sociedade, contra o próprio Estado. A nova feição do Ministério Público, na verdade, inibiu a atividade do estado na política de atuação criminal e repercutiu de maneira definitiva nas atividades do Ministério Público no âmbito da persecução penal ${ }^{3}$.

Com efeito, o art. 129 da Constituição Federal é o símbolo da transformação democrática do Ministério Público. Isso porque confere como funções institucionais tanto a promoção privativa da ação penal pública e o controle externo da atividade policial, quanto o zelo e respeito dos poderes públicos e dos serviços de relevância pública aos direitos assegurados na Constituição, dentre os quais a segurança pública (arts. 5. ${ }^{\circ}$ e $6^{\circ}$ ). O constituinte delegou-lhe prerrogativas para a promoção das medidas necessárias para proteção dos serviços públicos e de relevância pública, sem prejuízo de conferir-lhe a promoção do inquérito civil (e consequente capacidade investigatória), assim como da ação civil pública para a proteção do patrimônio público e social, do meio ambiente e de outros interesses difusos, coletivos e individuais homogêneos de caráter indisponíveis.

Contudo, na área criminal a instituição já se conformou ao modelo concebido pela Constituição Federal ou continua atuando de forma similar ao contexto da legislação penal e processual penal idealizada no contexto da década de quarenta do século passado?

O Ministério Público precisa e deve discutir, para efetivar sua conformação ao perfil pensado pelo constituinte, sua própria Política Criminal que inclua necessariamente: $a$ ) sua participação na Política Criminal através da concepção de uma Ciência Penal total; $b$ ) a construção de uma Política Criminal própria que discuta o trato da política de segurança pública como bem difuso que merece ser protegido, traçando estratégias para tanto; c) a construção de uma doutrina institucional de investigação criminal e de controle externo da atividade policial, assim como a fixação de parâmetros que permitam aferir sua eficiência e desempenho na diminuição das taxas de criminalidade, modificando-se, pois, toda sua estruturação de fiscalização e prestação de contas; $d$ ) a atuação, a partir da implementação de laboratórios de jurimetria, sob a forma de agências que, além de corpo técnico — analistas de dados, peritos, etc.— seja

3 Cfr. nesse sentido P. H. Demercian, Regime Jurídico do Ministério Público no Processo Penal, São Paulo, Verbatim, 2009, pp. 73-74. 
criada e pensada de acordo com as disfunções sociais e não simplesmente por território ${ }^{4}$.

Para além de todos esses relevantes aspectos, impõe-se a implementação de políticas de atuação resolutivas, pautadas no processo penal de resultados, isto é, o processo penal consensual, que já é uma realidade em países desenvolvidos no mundo.

O Ministério Público no Brasil recebeu do constituinte de 1988, tratamento singular no contexto da história do constitucionalismo brasileiro, reconhecendo-lhe uma importância de magnitude inédita inclusive frente ao direito comparado 5 .

Com efeito, o art. 129 da Constituição Federal é o símbolo da transformação democrática do Ministério Público. Isso porque confere como funções institucionais tanto a promoção privativa da ação penal pública e o controle externo da atividade policial, quanto o zelo e respeito dos poderes públicos e dos serviços de relevância pública aos direitos assegurados na Constituição, dentre os quais a segurança pública (arts. $5 .^{\circ}$ e $6 .^{\circ}$ ). O constituinte delegou-lhe prerrogativas para a promoção das medidas necessárias para proteção dos serviços públicos e de relevância pública, sem prejuízo de conferir-lhe a promoção do inquérito civil (e consequente capacidade investigatória), assim como da ação civil pública para a proteção do patrimônio público e social, do meio ambiente e de outros interesses difusos, coletivos e individuais homogêneos de caráter indisponíveis.

A Constituição Federal estabelece que o Ministério Público é instituição permanente e essencial à função jurisdicional do Estado, incumbindo-lhe a defesa da ordem jurídica (legalidade), do regime democrático e dos interesses sociais e individuais indisponíveis (Cfr. art. 127, caput). Estes princípios dão à Instituição sua conformação orgânica, fundada na unidade, indivisibilidade e independência funcional (C.F., art. 127, $\mathbb{\$} 10^{\circ}$ ). Não se desconhece que a Constituição deu ao Ministério Público autonomia político-administrativa, reservando-lhe, ipso facto, o poder de dirigir e administrar os assuntos de sua própria competência. $\mathrm{Na}$ prática, isto significa que a Instituição não se submete a qualquer outro poder do Estado, assumindo, na inter-relação com outros entes da administração, plena independência para gerir o próprio destino e atuar, na formação do seu convencimento, com liberdade e livre de interferências externas.

\footnotetext{
${ }^{4}$ A. R. A. De Moraes, Direito Penal Racional, Curitiba, Juruá Editora, 2016, p. 289

5 G. F. Mendes, I. M. Coelho y P. G. G. Branco, Curso de Direito Constitucional,

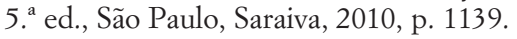


O princípio da autonomia — que suscita muita dissidência no direito estrangeiro- entre nós não gera maior perplexidade e diz respeito, especificamente, às relações externa corporis. Insere-se, portanto, no âmbito da apreciação da chamada separação de poderes e no sistema de freios e contrapesos estabelecido pela Constituição Federal, que representa um dos pilares do estado democrático, do qual a instituição é guardiã.

A Constituição Federal atribui, portanto, ao Ministério Público, a defesa da ordem jurídica. Não se trata, aqui, de uma expressão meramente retórica e vazia de significado. No âmbito criminal, a defesa da ordem jurídica, que está indissoluvelmente ligada à regra que atribui ao Ministério Público a titularidade da ação penal pública (cfr. art. 129, I), traduz, na sua essência, o dever do Promotor de Justiça de atuar nos estritos limites da lei (princípio da obrigatoriedade) e com objetividade.

Aliás, é corrente a afirmação de que o Ministério Público, por sua própria natureza, isto é, de órgão que não defende um interesse particular ou de particular ${ }^{6}$, deva agir com imparcialidade, o que não parece correto. Não se pode confundir essa característica peculiar do Poder Judiciário - a imparcialidade - com objetividade. Por comportamento objetivo (e não imparcial) do Ministério Público deve-se entender, como já se disse, não apenas a obediência estrita à legalidade, mas, principalmente, uma atuação isenta de idiossincrasias e paixões, que respeite o princípio da isonomia.

Com efeito, esse comportamento objetivo, que deve plasmar a atuação do órgão do Ministério Público, torna-se tanto mais evidente quando se the impõe o dever de fundamentar suas manifestações processuais (cfr. art. 129, inc. VIII).

Constitui, portanto, grave erro jurídico dizer-se que o Ministério Público, por ser parte no processo penal, não representa a sociedade. Esse tipo de asserção é meramente panfletária e absolutamente vazia de significado.

Em decorrência do monopólio da ação penal pública, o Ministério Público, a partir da Constituição Federal de 1988, perdeu o papel de advogado do Estado e se transformou, exclusivamente, em advogado da sociedade: a sociedade-governante. Esse aspecto fundamental na conformação Ministerial impõe à Instituição a formatação de políticas criminais que norteiem sua atuação como órgão indivisível.

Com efeito, a Carta Constitucional atribuiu-lhe o dever de zelar pelo respeito aos direitos nela assegurados (art. 129, II), ressaltou-lhe, como se

\footnotetext{
${ }^{6}$ Note-se que o Promotor de Justiça não aceita causas e tampouco representa partes. Cfr. nesse sentido A. Cluny, Pensar o Ministério Público Hoje, Lisboa, Cosmos, 1997.
} 
viu, o caráter de órgão de defesa da ordem jurídica, do regime democrático e dos interesses sociais indisponíveis (cfr. art. 127, caput).

Para o exercício dessas relevantes funções, o constituinte garantiu aos membros do parquet a inamovibilidade e vitaliciedade, preservando-lhes, ainda, a independência funcional.

$\mathrm{Na}$ verdade, as duas primeiras garantias, aliadas à irredutibilidade de vencimentos, asseguram a formação da livre convicção do órgão da acusação, que, dessa forma, age com independência e livre de ingerências externas.

Da conjugação dessas regras e do propósito de se conferir efetiva e especial proteção a todos os interesses envolvidos na persecução penal, com destaque para a tutela da liberdade pessoal e, de resto, para os diversos aspectos ligados ao devido processo penal (acusatoriedade, contraditoriedade, ampla defesa, paridade de armas, etc.), é que se tem extraído o chamado princípio do Promotor Natural, que foi concebido com a preocupação de limitar o arbítrio estatal no desenvolvimento do processo.

$\mathrm{Na}$ doutrina brasileira há um conceito que se pode dizer unívoco sobre o princípio da unidade e o seu consectário lógico que é a indivisibilidade. Parece não haver controvérsia no sentido de que unidade significa que os membros do Ministério Público fazem parte de um único órgão sob a direção de um só chefe.

A indivisibilidade, por sua vez, como decorrência do princípio antecedente, significa que os membros do Ministério Público atuam no processo como Instituição e esgotam a atividade desta no momento em que se manifestam, podendo, por isso mesmo, na forma da lei, ser substituídos uns pelos outros. Esse conceito corrente de unidade —visto sob o seu aspecto meramente formal—é, por si, inútil e não tem significado algum. Daí a razão de não tem despertado grande interesse da doutrina que se propõe a estudar o Ministério Público. $\mathrm{Na}$ verdade, ele pode ser aplicado rigorosamente a qualquer instituição pública (Poder Executivo, Poder Legislativo e Poder Judiciário).

Ninguém há duvida, por exemplo, que o Poder Judiciário é uno, deles fazem parte os juízes de direito (que gozam de independência) e que estão, pelo menos no aspecto administrativo, sujeitos a uma chefia ( $v$. gr. Presidente do Tribunal).

Há, contudo, diferenças sensíveis quando, comparativamente, se busca perquirir o significado do princípio da unidade no Poder Judiciário e no Ministério Público. A unidade das decisões judiciais está revestida, sem dúvida alguma, de maior fragilidade. Com efeito, antes de tudo, está sujei- 
ta a um impulso externo e, bem por isso, não se aplica a todos os processos. Em outras palavras, a manifestação unitária do Poder Judiciário conta com diversos filtros e sempre resulta da necessária colaboração da parte, isto é, os órgãos de jurisdição superior só se manifestam se para o caso específico houver previsão de recurso e ele efetivamente for interposto no prazo e na forma que a lei prevê. Mesmo o Supremo Tribunal Federal, órgão máximo do Poder Judiciário, só age por provocação e está necessariamente preso ao critério da imparcialidade.

A esta altura já é possível entrever a razão pela qual o constituinte destacou, dentre os princípios fundamentais do Ministério Público, exatamente a unidade e não o fez, por exemplo, em relação ao Poder Judiciário.

É que o campo de incidência da unidade do Parquet, ao reverso do que se verifica em outros entes estatais, é essencialmente funcional. Esse princípio do Ministério Público é pleno de significação e aplicabilidade. A unidade, mais do que sugere a definição, tem a relevante e indeclinável finalidade de preservar a isonomia de tratamento dos arguidos (objetivo, aliás, precípuo de um processo penal baseado no garantismo) e busca viabilizar uma resposta célere, eficaz e coordenada à sociedade quanto aos métodos e medidas empreendidas no combate às mais variadas formas e expressões da criminalidade.

Como já se disse, o Ministério Público se faz presente, nas suas funções institucionais, por seus órgãos de execução, dotados de poderes jurídicos para praticar os atos da pessoa coletiva, que através deles «conhece, pensa e quer» ${ }^{7}$. Tais órgãos, nos limites de suas atribuições, são o Ministério Público, cuja vontade expressam e ao qual seus atos devem ser imputados.

Independência e autonomia funcionais não constituem privilégios pessoais, mas prerrogativas indissociáveis do dever funcional, para cuja realização se preordenam. Em síntese, o Ministério Público — seja no âmbito cível, seja no âmbito criminal— sempre foi e será o representante da sociedade: a sociedade-governante, opondo-se, de forma recorrente, ao estado-aparato e enfrentando no seu dia-a-dia verdadeiros projetos criminosos de poder. Para tanto, deve buscar caminhos e instrumentos eficazes de atuação, que deverão pautar a eficiência de sua política criminal.

${ }^{7}$ Cfr. M. Caetano, Manual de Direito Administrativo, Lisboa, Coimbra, 1965, p. 154.

Foro, Nueva época, vol. 22, núm. 1 (2019): 101-118 


\section{A BUSCA PELA EFICIÊNCIA NA POLÍTICA CRIMINAL: A JUSTIÇA CONSENSUAL ${ }^{8}$}

\section{Aspectos introdutórios}

Não há novidade na constatação de que, sob a ótica meramente funcionalista, há uma influência decisiva do binômio tempo-eficiência, isto é, o processo deve terminar no menor tempo possível e com a máxima eficiência.

A rápida solução para controvérsias, de maneira mais eficiente do ponto de vista da economia processual, avulta na sociedade contemporânea, notadamente nas duas últimas décadas, que são marcadas pelo extraordinário desenvolvimento e sofisticação dos meios de comunicação. Trata-se da ideia de «Aldeia Global»" ${ }^{9}$ criada pela velocidade instantânea das informações em circulação pelo mundo e que repercute no direito penal e no processo penal, criando expectativas de eficiência, funcionalidade e celeridade.

Impõe-se, nessa medida, a análise específica do aspecto mais restrito da instrumentalidade do processo e direito penal ${ }^{10}$, isto é, sua face empírica, pautada no consenso e na diversão.

Há que se buscar instrumentos que permitam concretamente a resolução de conflitos num tempo razoável, respeitadas e observadas rigorosamente as garantias individuais ligadas ao devido processo, e, em última análise, aos axiomas do garantismo que emanam da Constituição Federal.

Nossa análise, no presente artigo, está centrada, num primeiro momento, ao modelo de Justiça consensual, racional e orientada para resultados, em suas diversas manifestações, como instrumentos eficientes para a distribuição da Justiça e o encerramento dos conflitos criminais no menor

${ }^{8}$ Cfr. nesse sentido P. H. Demercian e A. R. A. De Moraes, «Um Novo Modelo de Atuação Criminal para o Ministério Público Brasileiro: agência e Laboratório de Jurimetria», Revista Jurídica de Escola Superior do Ministério Público de São Paulo, vol. 11, núm. 1 (2017), pp. 22-24.

9 A expressão é de Marshall MacLuhan, para muitos o pensador que antecipou o surgimento da internet. Cfr., nesse sentido S. ALCIDES, «Valéry on line, Mcluhan off-line», em $O$ Futuro não é mais o que era, Rio de Janeiro, Artepensam, 2012, p. 93.

${ }^{10}$ Há quem negue, peremptoriamente, a finalidade instrumental do processo, sob o falso argumento de que ele está em situação de antinomia com a atual conformação Constitucional brasileira, especialmente a teoria dos direitos fundamentais. Cfr. nesse sentido A. de M. Rosa, Processo Penal Eficiente? Não, obrigado, Rio de Janeiro, Lumen Juris, 2010, p. 43. 
tempo possível, com menor custo social e dentro do modelo garantista que norteou a Constituição da República.

Além disso, como salienta Vasco Rodriguez ${ }^{11}$, a nenhum jurista atualizado terá passado despercebida a progressiva invasão da dogmática tradicional pelos novos conceitos da análise econômica do direito (AED), teoria que teve sua gênese nos Estados Unidos, no início da década de 60, inicialmente nos domínios do direito privado com três vertentes: a Escola de Chicago, a Escola de Yale e a terceira via defendida por Mercado Pacheco.

A teoria do Law and Economics já encontrou campo fértil no âmbito do direito processual penal —evidenciado pelo processo penal de resultadosbem como no direito penal, pautando-se pela análise da escolha racional, pelo equilíbrio e por critérios de eficiência, efetividade e eficácia, paradigmas naturais na prestação do serviço público (art. 37, CF).

No Brasil, no entanto, um agir assim, seja na produção legislativa, seja nos órgãos que integram o sistema de justiça e de segurança, ainda estão muito distantes ou, quando muito, apresentam-se de forma incipiente e não institucionalizada.

As tentativas de reformas legislativas não têm surtido os efeitos desejados, seja porque extremamente fragmentadas, tímidas e revestidas - como se disse anteriormente- de mero caráter simbólico, seja porque violadas por antigas práticas burocratizantes, que lhes desvirtuam a própria essência.

Dois exemplos clássicos dessa afirmação podem ser encontrados justamente na Justiça Consensual (a timidez com que as regras do processo negociado foram concebidas, restringindo-se, em boa medida, aos juizados especiais criminais, em que o conceito de menor potencial ofensivo foi decidido por uma ficção pautada na pena e não pelos bens protegidos) e a adoção dos princípios de um processo oral (adotados e aplicados de forma incompleta, com os vícios burocratizantes hauridos dos processos escritos).

Em outras palavras, há necessidade de empenho e vontade política para se romper com sistemas e métodos que, embora arraigados ao usus fori, já se mostraram ineficientes. Nesse esteio, busca-se demonstrar que as técnicas e instrumentos que decorrem de justiça negociada, orientada por critérios de transparência e eficiência na tomada de decisões (para legislar, prevenir, investigar e processar) podem ser ampliados, sem perplexidades e sem o risco de ofensa às garantias individuais, e os métodos de

${ }^{11}$ V. Rodrigues, Análise Econômica do Direito, 2. ${ }^{\text {a }}$ ed., Coimbra, Almedina, 2016, p. 7. 
análise das ciências econômicas —a análise econômica do direito (AED) não violam, se tomadas antes de tudo como um método de agir, as regras garantistas que devem permear a nossa política criminal.

\section{O processo penal de resultados: um modelo de Justiça consensual e racional}

Há uma tendência mundial para o chamado processo penal de resultados, que tem por escopo, em apertada síntese: a) solução rápida e eficiente dos litígios; $b$ ) a desburocratização da Justiça e sua maior aproximação ao ser consumidor; c) permitir que o Magistrado e Ministério Público, mais do que solucionadores de mazelas e doenças, atentem para uma postura preventiva e, quando não possível, de mediadores de conflitos.

É nesse contexto que se insere a Justiça Consensual, em cuja espécie é possível identificar os modelos de justiça negociada (transação penal, suspensão condicional do processo, colaboração premiada, etc.). Evidencia-se, portanto, uma clara antinomia e contraposição entre o consenso e a justiça imposta ou conflitual ${ }^{12}$.

Não se está propondo a adoção do modelo estadunidense em sentido estrito, não só pela pluralidade de ordenamentos e heterogeneidade de fontes, mas principalmente pelas estruturas próprias e peculiares do Ministério Público e Poder Judiciário naquele País. Do mesmo modo, não se almeja a aplicação inflexível do chamado adversarial system que, ao mesmo tempo em que torna o magistrado um autêntico árbitro, dá ao órgão da acusação um amplo poder de negociação pautado em critérios absolutamente incompatíveis com o ordenamento brasileiro ${ }^{13}$.

A justiça consensuada pode e deve ser adaptada ao modelo adotado em nosso país, na busca da eficiência, sem que, para tanto, sejam sacrificados os axiomas processuais clássicos.

Quando se fala em eficiência do processo alguns equívocos recorrentes ou, pelo menos, exageros maniqueístas merecem análise. De um lado,

${ }^{12}$ Cfr. nesse sentido P. SoAres de Albergaria, Plea Bargaining (aproximação à Justiça Negociada nos EUA), Coimbra, Almedina, 2007, p. 18

${ }_{13}$ Para exemplificar, basta pensar no mecanismo do Discovery, por meio do qual acusação e defesa podem ter recíproco conhecimento dos elementos de prova têm à disposição. Essa troca de informações dá direito a conhecer, por exemplo, as testemunhas de acusação e muito menos o teor dos respectivos depoimentos, o que seria, a toda evidência, inimaginável em nosso ordenamento. 
os defensores do chamado processo de resultados, buscando, a qualquer custo, a máxima eficiência e economia processuais; de outro lado, os detratores da expressão eficiência, que veem nesse sistema uma forma de limitação de direitos e garantias individuais e afronta aos axiomas garantistas.

Esse preconceito pode ter origem na utilização do conceito em outros ramos da ciência, como a economia e administração.

Como relembra Scarance Fernandes, na administração, a ideia de eficiência liga-se ao bom uso dos meios ou recursos disponíveis, para se atingir um determinado resultado, previamente desejado, enquanto a eficácia prende-se ao atingimento de determinados fins. Complementa o autor, esclarecendo que eficiência e eficácia são caminhos necessários na busca da efetividade, ou seja, o resultado verdadeiro, concreto e empírico ${ }^{14}$.

Em direito, no entanto, os conceitos de eficiência e eficácia são facilmente identificáveis, de acordo com a finalidade do processo almejada (instrumental; garantia contra o arbítrio Estatal ou conjunto de instrumentos e procedimentos assecuratórios dos direitos e garantias das partes dentro de um processo justo). A efetividade, no entanto, que é o próprio atingimento do resultado verdadeiro ${ }^{15}$, apresenta-se na área do direito, especialmente o processual penal, como algo bastante fluido: paz social, vigência do estado de direito ou segurança pública e preservação da dignidade humana ${ }^{16}$.

Em outras palavras, em matéria de direito processual penal, os conceitos de eficiência, eficácia e efetividade — de acordo com os diversos cortes ideológicos que possam merecer- devem ser conjugados para se buscar um conceito e resultados adequados.

Não parece possível, no contexto de um Estado Democrático de Direito, conceber-se um processo que busque, a todo custo e com a máxima economia processual, a punição, como também não é razoável que em nome da suposta preservação de premissas garantistas, o abuso no emprego de um falso sistema de direitos, de modo a sacrificar a segurança pública e paz social.

Em suma, não é por meio de uma fórmula matemática e economicista que se atingirá a paz social e tampouco por meio de digressões ucrônicas, filosóficas e divorciadas da realidade que se poderá assegurar, no pro-

${ }^{14}$ Nesse sentido A. S. Fernandes e M. Zilli (coords.), Terrorismo e justiça penal: reflexões sobre a eficiência e o garantismo, Belo Horizonte, Fórum, 2014, p. 19.

15 O. A. Batista JúnIor, Princípio Constitucional da eficiência administrativa, Belo Horizonte, Mandamentos, 2004, p. 113.

16 A. S. FeRnANDES e M. ZILLI (coords.), Terrorismo e justiça penal: reflexões..., op. cit., p. 25. 
cesso, um resultado justo, indene aos arbítrios estatais e que, ao mesmo tempo, evite a perda de referências cognitivas na ideia de Estado de Direito e fomente o justiçamento privado.

Portanto, um processo penal eficiente tem um claro caráter instrumental, concreto, empírico, dentro de um sistema de direitos e garantias das partes, assegurados num procedimento que se desenvolva num prazo razoável, para se atingir um resultado justo. Dentro dessa ótica, é perfeitamente possível a compatibilização do processo penal consensual, dos procedimentos abreviados e de regras típicas do processo oral, com um processo de inspiração garantista e não retoricamente paternalista.

Há quem negue, como dissemos, peremptoriamente o caráter instrumental do processo, com argumento que beira o silogismo erístico, ou seja, de que o consenso em matéria penal representará a ocisão dos direitos e garantias individuais, que não são compatíveis com o poder dispositivo das partes.

O equívoco nesse entendimento parece estar centrado, em primeiro lugar, na ideia maniqueísta que contrapõe (e não admite a conjugação) entre o poder punitivo Estatal e as garantias individuais que emanam do devido processo legal; em segundo lugar, na falsa premissa de que um processo penal consensual (Justiça Negociada) é inconciliável com a preservação dos direitos e garantias individuais e o devido processo legal, isto porque, no primeiro caso, o direito em jogo tem índole patrimonial, privada e disponível; e, a segunda hipótese, cuida de interesse público e indisponível.

Para os defensores radicais desse ponto de vista, o réu não é objeto do processo (como se via na origem do processo) e nem sujeito de direitos (como é encarado no direito contemporâneo), mas um autêntico objeto de estudo acadêmico, enquanto o processo nada mais é do que um fenômeno a ser dissecado e estudado academicamente.

Em outras palavras, o acusado nesse processo penal é alijado da sua autodeterminação. Trata-se de um ente desprovido de vontade e que não tem a capacidade de avaliar, para ele próprio, qual seria a melhor e mais conveniente maneira de enfrentar a opção Estatal em face da via reativa adotada, isto é, o consenso ou o conflito.

Como já sustentamos alhures, imagine-se, por exemplo, que fosse adotado no direito brasileiro o consenso em maior amplitude. Tome-se o delito de roubo, para análise: dispõe o julgador de generosa escala (quatro a doze anos de reclusão), para acomodar os diversos episódios delituosos.

Uma lei que autorizasse o Ministério Público a oferecer, $v$. gr., uma proposta de quatro anos de reclusão, em regime aberto ou cinco anos de 
prisão, com sanção restritiva de direitos por igual periodo, seria considerada inconstitucional, pois o réu não teria o poder dispositivo. A única via reativa, portanto, seria o processo criminal, não raro demorado e que, por esta razão, apenas prolongaria a agrura do próprio réu, sujeitando-o, ainda, em tese, a uma sanção mais rigorosa do que aquela proposta incialmente e, o que é mais grave, em regime fechado.

Além disso, não seria desarrazoado afirmar-se que essa rigorosa punição poderia ocorrer num momento em que não mais se mostrasse, do ponto de vista individual ou social, necessária e suficiente, posto que não alcançada pela prescriçãã ${ }^{17}$.

Em outras palavras, seria razoável exigir-se do réu a submissão a uma pena mais gravosa, em nome de uma suposta medida garantista, que lhe retira o poder dispositivo e a possibilidade de chegar a um consenso que, concretamente, lhe seja mais favorável? Por certo, a resposta é negativa.

$\mathrm{O}$ falso conceito de que consenso e garantismo são institutos que necessariamente se contrapõem e excluem, talvez esteja fundado, como se disse, num modelo de Justiça Negociada oriunda do direito norte-americano, cujos vícios encontrarão consistente proteção na sistemática brasilei$\mathrm{ra}$, na qual se adota, dentre outras técnicas, o chamado inquisitorial system, que não retira do juiz o poder instrutório e não o coloca como um mero espectador inerte, permitindo-lhe inclusive, quando for o caso, declarar o réu indefeso.

Um processo penal eficiente e eficaz é aquele que permita, no menor tempo possível, dentro do critério da razoabilidade, dentro da estrita legalidade e observância aos direitos e garantias individuais ligados ao devido processo legal, o atingimento de um resultado que seja justo e se aproxime do fim colimado, qual seja, a segurança pública e a paz social, mas não à custa de subtrair do indivíduo — da forma que melhor lhe conviertodos os instrumentos de defesa contra o eventual abuso do poder punitivo Estatal.

Já a política criminal racional deveria ser aquela que, longe de adivinhações, é planejada e traçada para uma atuação preventiva menos custosa socialmente e para uma investigação e repressão mais eficientes.

${ }^{17}$ É cediço daqueles que atuam na Justiça Criminal, que determinados processos se estendem por mais de cinco ou seis anos, até que se tenha uma decisão definitiva proferida pelas mais altas Corte do país. Durante todo esse periodo, é possível que o réu aguarde em liberdade (em homenagem ao princípio do estado de inocência) e, depois de tanto tempo, seja recolhido ao cárcere, num momento em que, talvez, já tenha estruturada uma nova vida e meditado suficientemente sobre a falta cometida. 
Nesse sentido, repita-se, no contexto da pós-modernidade (novos bens alçados à proteção jurídico-penal, globalização e revolução dos meios de comunicação), frente às novas formas de criminalidade que muito se distanciam do modelo clássico de inspiração iluminista (criminalidade organizada transnacional, terrorismo, criminalidade econômico-financeira) e, sobretudo, no contexto de um Estado Democrático de Direito, a política criminal (política legislativa, do sistema de segurança e agentes do sistema de justiça), tem o dever de ser construída orientada para as consequências, com critérios mínimos de racionalidade e eficiência.

\section{CONCLUSÕES}

Com especial atenção à advertência de José Carlos Barbosa Moreira, no sentido de que «...nenhuma "revolução" puramente processual é suscetível, por si só, de produzir, na estrutura jurídico-social, modificações definitivas.... ${ }^{18}$, e considerando que a sensação de impunidade que se difundiu na opinião pública deve-se, em grande parte, ao sistema processual penal antigo (remontando a 1941) e dissociado da realidade, nossa proposta está assentada na premissa de que a legislação brasileira deve se alinhar, em definitivo, a estruturas que privilegiem a adoção de instrumentos consensuais para a solução de conflitos, de acordo com as peculiaridades do direito brasileiro, a partir da implementação, no Ministério Público, de laboratórios de jurimetria, sob a forma de agências que, além de corpo técnico - analistas de dados, peritos, etc.- seja criada e pensada de acordo com as disfunções sociais e não simplesmente por território. Em suma, a adoção do processo penal consensual no Brasil deve ser precedida da necessária conformação do Ministério Público ao perfil traçado pela Constituição Federal de 1988, com a adoção de políticas criminais claras e consistentes de atuação.

\section{BIBLIOGRAFÍA}

Albergaria, P. S.: Plea Bargaining: aproximação à Justiça Negociada nos EUA, Coimbra, Almedina, 2007.

18 J. C. Barbosa Moreira, «A Função Social do Processo Civil Moderno e o Papel do Juiz e das Partes na Direção e na Instrução do Processo», Revista de Processo, núm. 37 (1985). 
Alcides, S.: «Valéry on line, Mcluhan off-line», in O Futuro não é mais o que era, Rio de Janeiro, Artepensam, 2012.

Barbosa Moreira, J. C.: «A Função Social do Processo Civil Moderno e o Papel do Juiz e das Partes na Direção e na Instrução do Processo», Revista de Processo, núm. 37 (1985).

Batista Júnior, O. A.: Princípio constitucional da eficiência administrativa, Belo Horizonte, Mandamentos, 2004.

Caetano, M.: Manual de Direito Administrativo, Lisboa, Coimbra, 1965.

CarneIro, P. C. P.: O Ministério Público no processo civil e penal: o promotor natural - atribuição e conflito, 4. ${ }^{\text {a }}$ ed., Rio de Janeiro, Forense, 1992.

Carvalho, P. P. de: «Uma incursão no Ministério Público à luz do Direito comparado: França, Itália, Alemanha, América do Norte e União Soviética», in V. de L. Moraes (org.), Ministério Público, Direito e Sociedade, Porto Alegre, Sérgio Antonio Fabris Editor, 1986.

Cluny, A.: Pensar o Ministério Público Hoje, Lisboa, Cosmos, 1997.

Demercian, P. H.: Regime Jurídico do Ministério Público no Processo Penal, São Paulo, Verbatim, 2009.

- «Apontamentos sobre o crime organizado, a Justiça Consensual e o valor probatório das declarações do corréu», in J. R. G. Carneiro e A. F. Messa (orgs.), Organizações Criminosas, São Paulo, Saraiva, 2012.

Demercian, P. H., e Moraes, A. R. A. de: Revista Jurídica de Escola Superior do Ministério Público de São Paulo - Um Novo Modelo de Atuação Criminal para o Ministério Público Brasileiro: agência e Laboratório de Jurimetria, vol. 11, núm. 1 (2017).

— «Um Novo Modelo de Atuação Criminal para o Ministério Público Brasileiro: agência e Laboratório de Jurimetria», Revista Jurídica de Escola Superior do Ministério Público de São Paulo, vol. 11, núm. 1 (2017), pp. 22-24

FERNANDES, A. S., e ZILLI, M. (coords.): Terrorismo e justiça penal: reflexões sobre a eficiência e o garantismo, Belo Horizonte, Fórum, 2014.

Lyra, R.: Teoria e Prática da Promotoria Pública, 2. ${ }^{a}$ ed., Porto Alegre, Sérgio Antonio Fabris, 1989.

Marques, J. F.: Elementos de Direito Processual Penal, vol. II, São Paulo, Saraiva, 1961.

Mazzilli, H. N.: Regime jurídico do Ministério Público, 2. ${ }^{a}$ ed., São Paulo, Saraiva, 1995.

Mendes, G. F.; Coelho, I. M., y Branco, P. G. G.: Curso de Direito Constitucional, 5. ed., São Paulo, Saraiva, 2010.

Moraes, A. R. A. de: Direito Penal Racional: Propostas para a construção de uma teoria da legislação e para uma atuação criminal preventiva, 1. ${ }^{a}$ ed., Curitiba, Juruá, 2016.

Moraes, A. R. A. de, e Demercian, P. H.: «Um Novo Modelo de Atuação Criminal para o Ministério Público Brasileiro: agência e Laboratório de Jurimetria», 
Revista Jurídica de Escola Superior do Ministério Público de São Paulo, vol. 11, núm. 1 (2017).

Moreira, J. C. B.: «A Função Social do Processo Civil Moderno e o Papel do Juiz e das Partes na Direção e na Instrução do Processo», Revista de Processo, núm. 37 (1985).

Pontes de Miranda, F. C.: Comentários ao Código de Processo Civil, vol. I, Rio de Janeiro, Forense, 1974.

Rosa, A. de M.: Processo Penal Eficiente? Não, obrigado, Rio de Janeiro, Lumen Juris, 2010.

Rodrigues, V.: Análise Econômica do Direito, 2. ${ }^{a}$ ed., Coimbra, Almedina, 2016.

SoAres de Albergaria, P.: Plea Bargaining (aproximação à Justiça Negociada nos EUA), Coimbra, Almedina, 2007. 